\title{
Stem cells: a model for screening, discovery and development of drugs
}

\author{
Satish Srinivas Kitambi' \\ Gayathri Chandrasekar² \\ 'Department of Medical Biochemistry \\ and Biophysics; ${ }^{2}$ Department of \\ Biosciences, Karolinska Institutet, \\ Stockholm, Sweden
}

This article was published in the following Dove Press journal:

Stem Cells and Cloning: Advances and Applications

26 September 201I

Number of times this article has been viewed

\begin{abstract}
The identification of normal and cancerous stem cells and the recent advances made in isolation and culture of stem cells have rapidly gained attention in the field of drug discovery and regenerative medicine. The prospect of performing screens aimed at proliferation, directed differentiation, and toxicity and efficacy studies using stem cells offers a reliable platform for the drug discovery process. Advances made in the generation of induced pluripotent stem cells from normal or diseased tissue serves as a platform to perform drug screens aimed at developing cell-based therapies against conditions like Parkinson's disease and diabetes. This review discusses the application of stem cells and cancer stem cells in drug screening and their role in complementing, reducing, and replacing animal testing. In addition to this, target identification and major advances in the field of personalized medicine using induced pluripotent cells are also discussed.
\end{abstract}

Keywords: therapeutics, stem cells, cancer stem cells, screening models, drug development, high throughput screening

\section{Introduction}

The advent of technology and a plethora of experimental work have unequivocally established the existence of stem cells in many tissues. ${ }^{1-8}$ Cell self-renewal, ie, the ability to produce an identical copy of itself, and multipotency, ie, the ability to generate cells different from itself, are fundamental characteristics of a stem cell. The ability to self-renew or be multipotent varies between different stem cells and is referred to as "stemness". ${ }^{9}$ These are unique qualities that have allowed both academia and industry to foresee the application of stem cells in various diseases/disorders and medical challenges, like Parkinson's disease, Alzheimer's disease, diabetes, multiple sclerosis, heart disease, cancer, spinal cord injury, wound healing, and organ transplantation (Figure 1). ${ }^{10-22}$ Recent advances in the treatment of graft versus host disease ${ }^{23}$ and the success of hematopoietic stem cell transplants ${ }^{21}$ have made it possible to envisage stem cells as a potential reservoir to meet our unmet medical needs.

In addition to the wide array of applications in the field of regenerative medicine, the possibility of performing high-content drug screens as well as toxicity and efficacy studies has enabled stem cells to become a valuable resource in the field of drug discovery and pharmaceutical research. ${ }^{24,25}$ The recent demonstration of reprogramming of somatic cells into "embryonic stem cell-like" induced pluripotent stem cell ${ }^{26,27}$ has revolutionized pharmaceutical research by linking human disease, patient specificity, and drug discovery. This process could not only lead to the development of various cellular therapies, but also push the boundaries of personalized medicine. The availability 


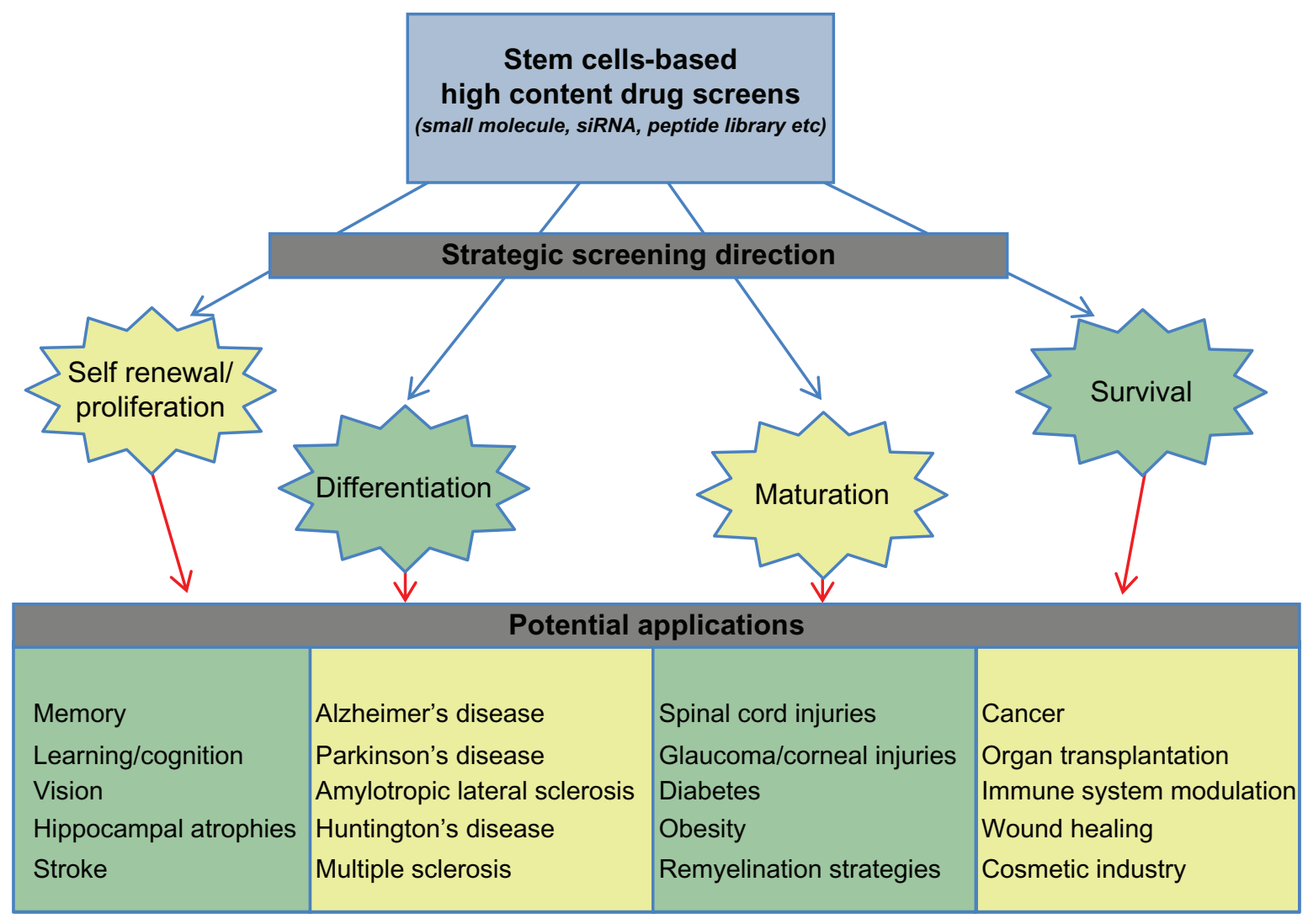

Figure I Overview of the focus areas for developing stem cell-based screening strategies and their potential application in different human diseases and disorders.

and ever-evolving methodologies used to isolate human (or animal) embryonic stem cells, adult tissue-specific neural stem cells, and human induced pluripotent stem cells ${ }^{28}$ have led to the development of various high throughput and combinatorial screening technologies, ${ }^{29-31}$ thereby augmenting the role of stem cell models in drug discovery.

\section{Stem cells as in vitro models for drug discovery}

Drug testing using in vitro models has been a major boost, not only in identifying potential therapeutic compounds, but also in increasing our understanding of their absorption, distribution, metabolism, and excretion (ADME) properties. ${ }^{32}$ The development of various in vitro ADME models has made a clear impact on the pathway towards modernizing and accelerating drug discovery and development. A clear proof of principle can be seen in the case of terfenadine in the late $1980 s,{ }^{33}$ whereby use of an in vitro ADME system enabled researchers to understand torsades de pointes, an often fatal cardiac arrhythmia. ${ }^{33,34}$ Tumor-derived or engineered immortalized cells obtained from human (or animal) sources have been the most common in vitro models used by the biotechnology and pharmaceutical industries. ${ }^{35,36}$ While these cell lines have the advantages of convenience and scalability of the screening process, they show high variability in their growth, abnormal genotype, and physiological response to drugs. The abnormalities associated with these immortalized cells restrict the confidence value and number of lead molecules for drug development. The use of specialized primary culture models like hepatocytes, human umbilical endothelial cells, and keratinocytes offer limited usage due to their restricted expandability. ${ }^{37-39}$

The need for an improved and uniform physiological response, normal genotype, and growth pattern has redirected drug discovery efforts towards stem cells. The possibility of isolating stem cells from a wide spectrum of tissues ${ }^{1-8}$ and growing them in vitro, as well as their ability to differentiate into a number of specialized cell types has provided an invaluable tool for drug/target discovery and validation. ${ }^{40}$ The use of stem cells will not only bring drug discovery costs down, but also improve the chances of identifying leads with a target or pathway relevant to the disease process and with a stronger potential for translation to clinical settings.

Although stem cells offer huge potential in the field of pharmaceutical research, their immediate applicability in the field of drug discovery is limited due to a variety of factors. 
For example, stem cells from different tissues are not the same,${ }^{19}$ and in vitro culture where the stem cells are flooded with growth factors is different from the microenvironment in which stem cells reside in vivo. ${ }^{41,42}$ Stem cells have a slower cell cycle than their progenitor cells in vivo, so the degree of sensitivity of readouts obtained in vitro may not be the same as in vivo. ${ }^{41,42}$ Stem cells isolated from tissues such as the liver, muscle, and adipose tissue have a limited ability to expand when compared with bone marrow-derived mesenchymal stem cells (Figure 2) ${ }^{19}$ In addition, stem cells derived from tissues like muscle and the liver lose their potential to differentiate upon repeated expansion, while undifferentiated hematopoietic stem cells expand poorly but can differentiate into all types of blood cells. ${ }^{43,44}$

Bone marrow-derived mesenchymal stem cells offer an attractive high throughput screening platform for new target/ drug discovery. These stem cells can be readily expanded in vitro and can be isolated from a variety of tissue sources, such as brain, lung, heart, muscle, and the umbilical cord. Bone marrow-derived mesenchymal stem cells have demonstrated scalability for drug screens and can be differentiated into neurons, adipocytes, muscle cells, chondrocytes, and osteocytes. These features of bone marrow-derived mesenchymal stem cells allow drug screens to be directed towards stem cell self-renewal, proliferation, differentiation, and a variety of disease-related drug discovery programs, eg, for cancer, obesity, diabetes, and central or peripheral nervous system disorders (Figures 1 and 3). ${ }^{45-49}$ The true power of stem cells in drug discovery programs will be fully realized when a readily expandable diverse panel of stem cells becomes available.

\section{Cancer stem cells in drug discovery}

Cancerous cells also exploit the same properties of selfrenewal and multipotency that make stem cells so attractive in regenerative medicine and drug discovery. Recent studies have identified a small unique population of cells known as cancer stem cells, or tumor-inducing cells, that reside in tumors. ${ }^{50}$ These cells arise from oncogenic transformation of either stem cells or progenitor cells. Cancer stem cells or tumor-inducing cells have "stem-like" character, a slow proliferation rate, a high capacity for self-renewal, resistance to standard chemical/radiation therapy, and a propensity to differentiate into actively proliferating tumor cells. ${ }^{50,51}$ Cancer stem cells have been isolated from many tumor types, including brain, renal, colon, and prostate tumors, as well as hematopoietic cancers, and therapeutic strategies are being developed to target cancer stem cells for apoptosis or cell cycle arrest specifically and thereby eradicate tumors more effectively than current treatments. ${ }^{51,52}$ Cancer drug discovery programs have, to a large extent, employed immortalized cell lines or primary tumor tissue for in vitro assay. This approach has been largely unsatisfactory in developing effective therapeutics for cancer. Cancer drug discovery programs involving cancer stem cells as a platform offer a discovery process with a high degree of therapeutic efficiency. ${ }^{53-55}$ This is particularly evident from the drug discovery process in leukemia. ${ }^{53}$ The fact that cancer stem cells feed the cancer growth and promote resistance to existing chemotherapeutic drugs makes them candidate cells for drug discovery screens. ${ }^{53-55}$ In cancer of the hematopoietic system, cancer stem cells have been well characterized in chronic myelogenous leukemia, acute myelogenous leukemia, and acute lymphoblastic leukemia. ${ }^{56-58}$ Drug discovery programs targeting CD33 in acute myelogenous leukemia and the ABL kinase inhibitor, imatinib mesylate, in chronic myelogenous leukemia have been very effective. Biomarkers such as CD33 have been shown to be uniquely characteristic of the cancer stem cells of acute myelogenous leukemia, and efforts to design immunotherapy against such biomarkers are becoming very useful. ${ }^{58-61}$

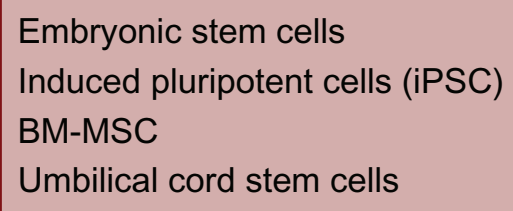

Epithelial stem cells Skin stem cells (hair follicle) Amnion stem cells Adipose stem cells
Hematopoietic stem cells Pancreas stem cells Liver stem cells Neural stem cells Cardiac stem cells Skeletal stem cells

\section{Expandability for high throughput drug screens}

\section{High}

Figure 2 Different types of stem cells and their potential to be used in large-scale screens. The different types of cells are arranged in three boxes indicating high, medium, and low expandability. 


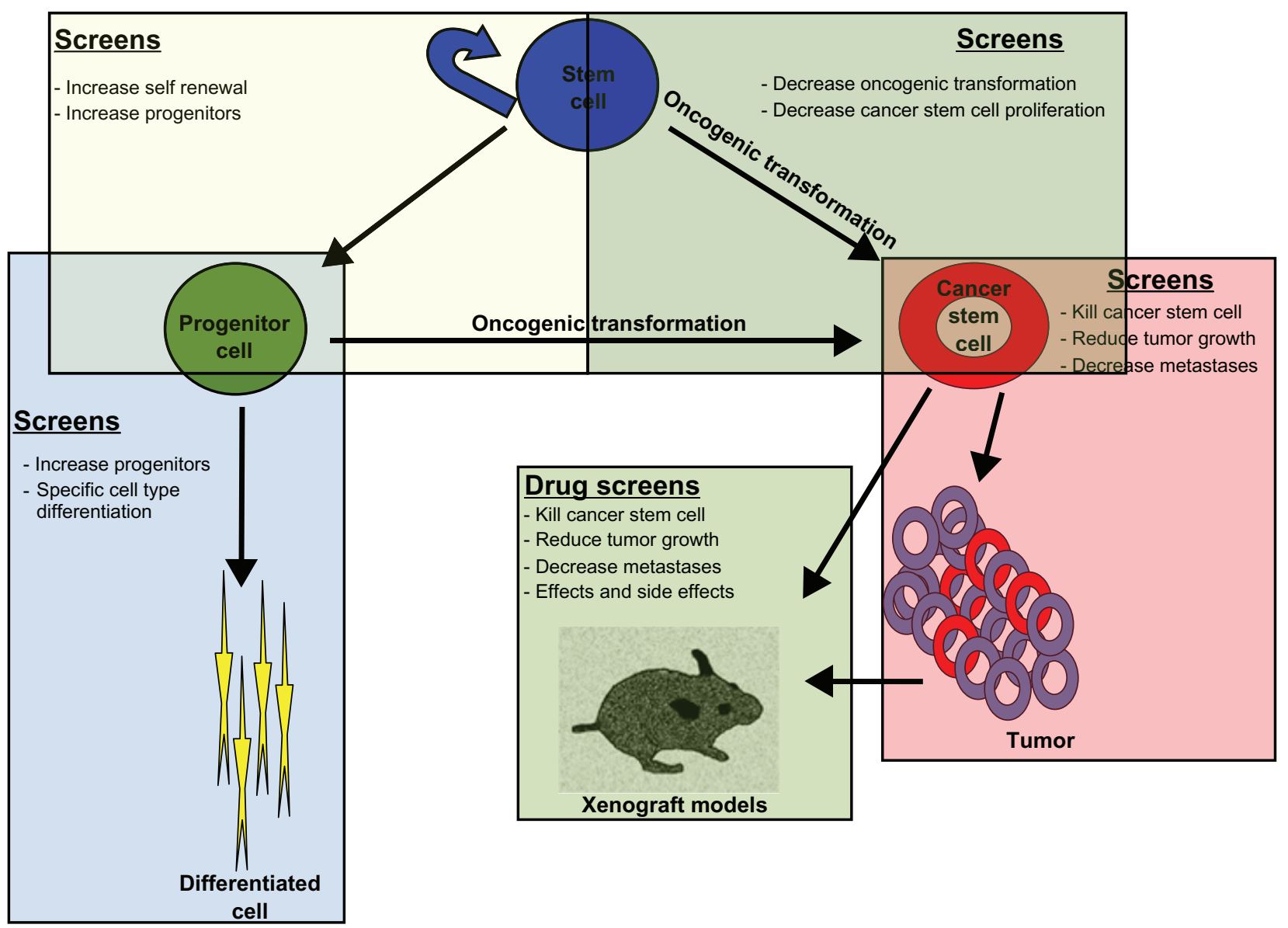

Figure 3 Targeted screens for drug development with immediate clinical applicability.

From the perspective of drug discovery and translational research, cancer stem cells provide a solid platform with significant implications for designing therapeutic approaches and developing long-term treatment (Figure 3). ${ }^{51,52}$ It has to be noted that in vitro propagation of cancer stem cells does not mimic factors governing the microenvironment of cancer stem cells, such as hypoxia, ${ }^{62}$ but they do offer a platform for evaluating drug screens with a higher degree of confidence, thereby facilitating preclinical trials and clinical trials of antitumor therapies. ${ }^{54}$ Research reports indicating that cancer stem cells can be selectively targeted without harming normal stem cells offers a possibility to perform targeted drug discovery screens against cancer stem cells from different tumors. ${ }^{63}$

\section{Stem cells complement animal models in drug discovery}

Stem cells have already received enormous attention for their potential in refining drug screens. Stem cell screens are a more cost-effective strategy than animal testing. They are also seen as a process of refining, reducing, and possibly replacing animal testing procedures. However, animal models offer a whole system setup for testing the effects and side effects of drugs. ${ }^{64-66}$ It has to be noted that the response to drugs in animal models may not be the same as in humans. Animal models differ from those in humans in a number of ways. In particular, they do not reflect the ethnic diversity of humans and their response to drugs may be different to that seen in humans. In addition, animal models are costly and time-consuming. Stem cells offer an alternate platform to overcome the limitations of ethnic diversity, provide a uniform response to a drug which can correlate with the human response, and are cost- and time-effective. Unfortunately, the current status of stem cell research does not allow us to substitute for whole animal testing, as seen with animal models. However, stem cells are very promising substitutes in terms of single organ toxicity. ${ }^{67}$ Embryonic or adult tissue-specific stem cells that can ultimately be grown into an entire human organ will be a gold standard for single organ drug testing.

Cell-based in vitro assays provide a scaffold to perform high throughput or high content screens (Figure 3), but 
they do not reflect the complex in vivo scenario. Cell-based screens do not take into consideration the cross-talk between organs (or different cell types) or the general metabolism and side effects seen in vivo. Hence in vitro assays have to be complemented with various in vivo assays using different animal models. Currently, various invertebrate and vertebrate models are available for screening the toxicity and efficacy of lead molecules.

Invertebrate models of Drosophila and Caenorhabditis elegans offer a powerful model suitable for drug discovery research. ${ }^{68-71}$ Their small size, short generation time, relatively low cost of housing and maintenance, highly conserved molecular pathways, and availability of various genetic and biochemical tools have made it possible to include them in multistep drug screening processes. ${ }^{69}$ The ease with which transgenics, overexpression, and mutation of proteins can be done, as well as the relatively simple genetic cascade involved have enabled their use in performing screens directed against Alzheimer's disease, Huntington's disease, oncogenic transformation, stem cell niche, metastases, neurodegeneration, apoptosis, and behavioral analyses. ${ }^{72-76}$ These simple models offer a setup whereby a particular process such as neurodegeneration can be quickly screened. For example, a Drosophila Huntington's disease model and transgenic line provide an ideal in vivo system for not only examining mutant Huntington gene-mediated cellular defects, such as impairment of axonal transport, but also facilitate rapid assays for screening and validating potential treatment to alleviate the observed cellular defects. ${ }^{77,78}$ The relatively simple metabolic and genetic cascades and the long evolutionary separation from humans are major disadvantages limiting the use of these models in drug development research.

Higher vertebrate models such as rabbits, dogs, monkeys, and rodents have been extensively used in drug safety testing. Among them, rodents are a very good complement to stem cell-based screening. The availability of knockins, conditional knockouts, and transgenic models forms a powerful support system to evaluate the in vivo response of various lead molecules identified in stem cell-based in vitro screens. ${ }^{79,80}$ The identification of a tissue-specific stem cell niche in rodent models ${ }^{81}$ offers the advantage of developing screens directed towards manipulation of the stem cell microenvironment to aid in understanding and developing therapeutic strategies for various diseases, such as neurodegenerative disorders, stroke, organ transplant, brain trauma, wound healing, and cancer. Such screens have identified molecules that affect the progenitor pool size of the adult neural stem cell population. ${ }^{82}$ However, the traditional methods of analysis in rodent models are slow and rely extensively on analyses of tissues collected from sacrificed animals.

In recent years, teleost vertebrate models, in particular zebrafish and medaka, have become popular models for studying various aspects of developmental biology and genetics. Their rapid external development, transparency of embryos, husbandry, and large sample size are some of the advantages readily offered by these models. ${ }^{83-85}$ The possibility of performing toxicity and efficacy screening of chemicals, pharmaceuticals, and pesticides that can be correlated in terms of human health risks are propelling this model as a choice for toxicological or pharmacological screens. Small molecule screening to identify and characterize a molecule that produces specific effects against various disease processes in humans has been successfully developed. ${ }^{86,87}$ The zebrafish (Danio rerio) has been more extensively used than the medaka (Oriyzas latipes), but both show a high degree of anatomical and physiological homology with that of other higher order vertebrates, and also have very similar cellular structure, signaling processes, and cognitive behavior. ${ }^{86,87}$ The collection of various mutant lines with defects in the development and function of the various metabolic processes, and the availability of various biochemical, molecular, and genetic techniques has facilitated the development of various in vivo drug screens targeting development, metabolism, and physiological conditions in terms of various human diseases. ${ }^{88,89}$

\section{Target identification and evaluation tools aiding stem cell-based drug discovery}

Drug discovery screens using stem cells are a new and immensely necessary resource (Figure 3 ). The most commonly used screening process involves growing cells as a monolayer culture and exposing them to libraries of new chemical entities. The final readout in most of the high throughput scenarios is based on imaging..$^{90}$ Imaging-based screens are quick and can be automated with ease. Time-lapse assays can also be performed to understand the onset of the phenotype. Imaging-based readouts can simply employ bright field images to understand the impact of the compound on colony size, morphology, proliferation, and cell number. These image-based readouts can also be combined with immunofluorescence to test the expression/ inhibition of markers of interest. Commercially available assays, which use fluorescent readouts to measure cell proliferation, apoptosis, and toxicity, can be employed with relative ease in a high throughput screen scenario. ${ }^{90-94}$ 
Other methodologies, such as quantitative polymerase chain reaction and fluorescence-activated cell sorting, can be performed at a low to medium throughput screening level and offer wide endpoint assays, such as measuring cell cycle and proliferation, as well as quantifying expression of biomarkers at the RNA or protein level. Techniques such as microarrays, chip-sequencing, single cell illumina-based sequencing, and proteomic approaches, eg, affinity column purification and matrix-assisted laser desorption ionization time-of-flight mass spectrometry, can be used effectively as a high-end analysis for target identification and characterization of the lead compound (Figure 4).

\section{Applications of stem cells in drug discovery}

One of the straightforward applications of stem cells lies in clarifying disease mechanisms and toxicity. Testing lead compounds for neuronal, hepatic, and cardiac toxicity would provide direct assessment of the effects and side effects of drugs. ${ }^{25}$ Embryonic or tissue-specific stem cells from normal individuals and diseased patients can be obtained and differentiated in neurons, hepatocytes, or cardiomyocytes for toxicity testing. ${ }^{95}$ In a scenario where stem cells are not available, somatic cells from normal individuals or diseased patients can be reprogrammed into induced pluripotent stem cells for further differentiation and toxicity testing. However, it has to be noted that the complete molecular nature of induced pluripotent stem cells has not been thoroughly evaluated, hence direct clinical translation of any screen done on induced pluripotent stem cells will not be possible in the near future. ${ }^{96}$ In neurodegenerative conditions like Parkinson's disease, stroke, Alzheimer's disease, and Huntington's disease, stem cell-based drug discovery programs will transform the way in which therapies are discovered and designed. ${ }^{19,95}$ Screens aimed at enriching stem cell populations or directing their differentiation into a particular cell type would be immensely beneficial in faster recovery from disease (Figure 3). Currently, various screens to isolate lead molecules capable of increasing the proliferation of stem cells, while preserving their "stem-like" properties and screens aimed at directed differentiation of stem cells are being performed in vitro. ${ }^{40}$ The recent development of technology that allows the reprogramming of somatic cells into induced pluripotent stem cells presents an opportunity to conduct screens on induced

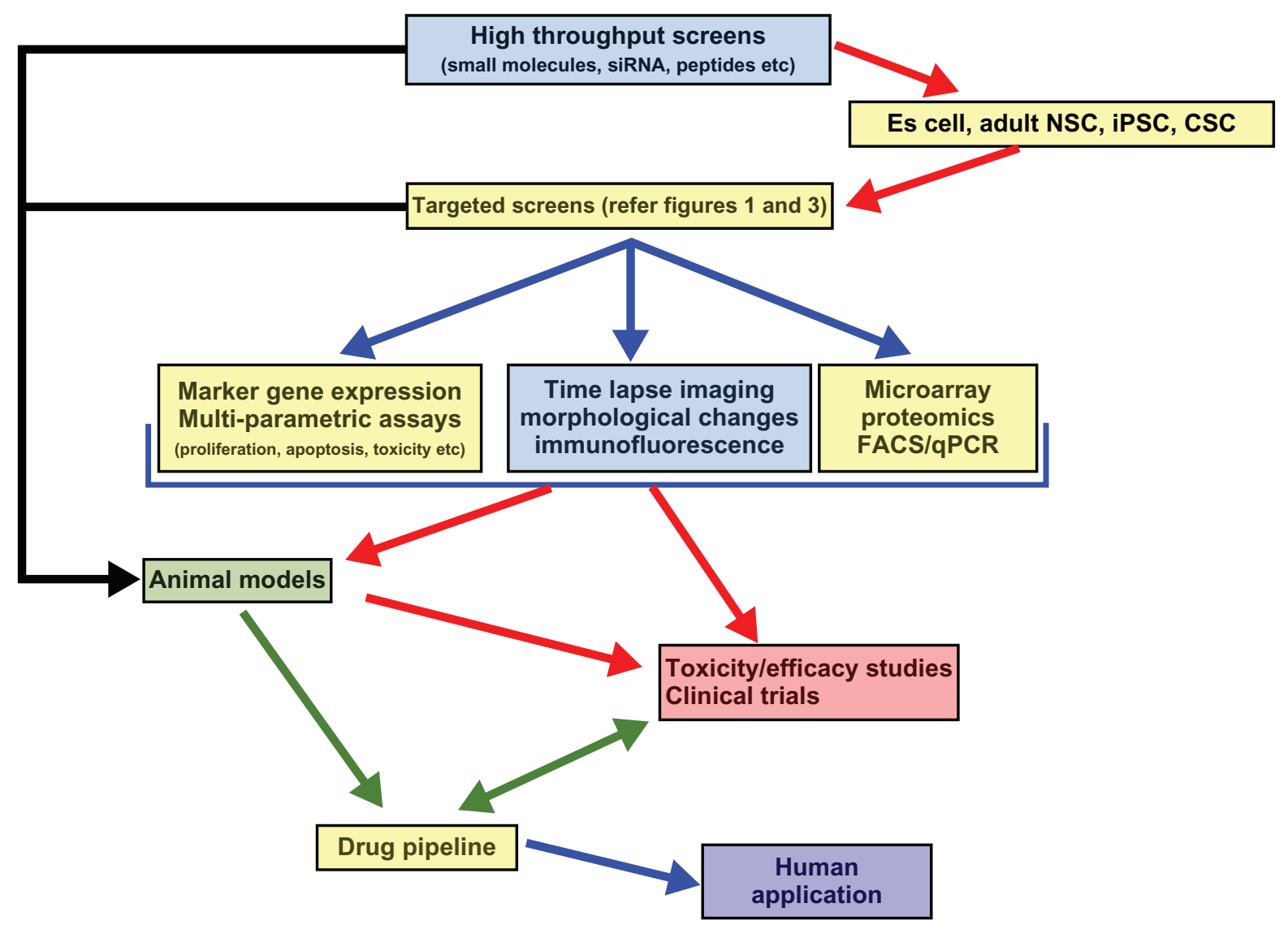

Figure 4 Overview of stem cell-based drug discovery process. 
pluripotent stem cells derived from patients with the aim of finding lead molecules that delay the onset of disease, speed up the recovery process, or possibly cure the disease. ${ }^{97}$ Stem cells or induced pluripotent stem cells could also act as transport agents for delivery of small molecules, therapeutic agents, or the correct version of a diseased gene in patients. ${ }^{98-100}$ Screens aimed at cancer stem cells would not only help us in designing better therapy, but also enable discovery of molecules that could result in a long-term disease-free state. ${ }^{101}$ It is very realistic to imagine creating normal or disease-specific human stem cell panels to aid in efforts for screening, discovery, and development of drugs.

\section{Conclusion}

In conclusion, stem cells (both normal and cancerous) are a valuable tool in the drug discovery process. They enable rapid identification of therapeutically useful molecules that can modulate normal and tumorigenic stem cell behavior (Figure 4). Although the direct clinical applications of human embryonic stem cells are limited due to ethical concerns and the potential for teratoma formation, they can still be heavily exploited as a tool in various high content screens directed towards self-renewal, multipotency, and differentiation. The identification of tissue-specific stem cells, cancer stem cells, and the recent development of induced pluripotent stem cells, offers an attractive opportunity for developing drug screens aimed at various human disease states. Drug screens and stem cell research have the potential to develop novel cellular and gene therapies that could be directly applied in the clinical treatment of various genetic and degenerative disorders.

\section{Acknowledgment}

The authors would like to thank Karolinska Institutets Forskningsstiftelser 2010 for financial support, Mr KV Padmanabhan and Mrs Srividya Seshadri for proof reading the text.

\section{Disclosure}

The authors report no conflicts of interest in this work.

\section{References}

1. Brittan M, Wright NA. Gastrointestinal stem cells. J Pathol. 2002;197(4): 492-509.

2. Bryder D, Rossi DJ, Weissman IL. Hematopoietic stem cells: the paradigmatic tissue-specific stem cell. Am J Pathol. 2006;169(2):338-346.

3. Bussolati B, Bruno $\mathrm{S}$, Grange $\mathrm{C}$, et al. Isolation of renal progenitor cells from adult human kidney. Am J Pathol. 2005;166(2):545-555.

4. Dhawan J, Rando TA. Stem cells in postnatal myogenesis: molecular mechanisms of satellite cell quiescence, activation and replenishment. Trends Cell Biol. 2005;15(12):666-673.

5. Kim CF, Jackson EL, Woolfenden AE, et al. Identification of bronchioalveolar stem cells in normal lung and lung cancer. Cell. 2005;121(6): 823-835.
6. Peault B, Rudnicki M, Torrente Y, et al. Stem and progenitor cells in skeletal muscle development, maintenance, and therapy. Mol Ther. 2007;15(5):867-877.

7. Schaffler A, Buchler C. Concise review: adipose tissue-derived stromal cells - basic and clinical implications for novel cell-based therapies. Stem Cells. 2007;25(4):818-827.

8. Van Vliet P, Sluijter JP, Doevendans PA, Goumans MJ. Isolation and expansion of resident cardiac progenitor cells. Expert Rev Cardiovasc Ther. 2007;5(1):33-43.

9. Burns CE, Zon LI. Portrait of a stem cell. Dev Cell. 2002;3(5):612-613.

10. Behfar A, Perez-Terzic C, Faustino RS, et al. Cardiopoietic programming of embryonic stem cells for tumor-free heart repair. J Exp Med. 2007;204(2):405-420.

11. Bujan J, Pascual G, Corrales C, Gomez-Gil V, Garcia-Honduvilla N, Bellon JM. Muscle-derived stem cells used to treat skin defects prevent wound contraction and expedite reepithelialization. Wound Repair Regen. 2006;14(2):216-223.

12. Chang YC, Shyu WC, Lin SZ, Li H. Regenerative therapy for stroke. Cell Transplant. 2007;16(2):171-181.

13. Gangaram-Panday ST, Faas MM, de Vos P. Towards stem-cell therapy in the endocrine pancreas. Trends Mol Med. 2007;13(4):164-173.

14. Gharaee-Kermani M, Gyetko MR, Hu B, Phan SH. New insights into the pathogenesis and treatment of idiopathic pulmonary fibrosis: a potential role for stem cells in the lung parenchyma and implications for therapy. Pharm Res. 2007;24(5):819-841.

15. Gimble JM, Katz AJ, Bunnell BA. Adipose-derived stem cells for regenerative medicine. Circ Res. 2007;100(9):1249-1260.

16. Goldman SA. Disease targets and strategies for the therapeutic modulation of endogenous neural stem and progenitor cells. Clin Pharmacol Ther. 2007;82(4):453-460.

17. Ma Y, Xu Y, Xiao Z, et al. Reconstruction of chemically burned rat corneal surface by bone marrow-derived human mesenchymal stem cells. Stem Cells. 2006;24(2):315-321.

18. McMullen NM, Pasumarthi KB. Donor cell transplantation for myocardial disease: does it complement current pharmacological therapies? Can J Physiol Pharmacol. 2007;85(1):1-15.

19. Mimeault M, Batra SK. Concise review: recent advances on the significance of stem cells in tissue regeneration and cancer therapies. Stem Cells. 2006;24(11):2319-2345.

20. Oh SH, Witek RP, Bae SH, et al. Bone marrow-derived hepatic oval cells differentiate into hepatocytes in 2-acetylaminofluorene/partial hepatectomy-induced liver regeneration. Gastroenterology. 2007; 132(3):1077-1087.

21. Small TN, Young JW, Castro-Malaspina H, et al. Intravenous busulfan and melphalan, tacrolimus, and short-course methotrexate followed by unmodified HLA-matched related or unrelated hematopoietic stem cell transplantation for the treatment of advanced hematologic malignancies. Biol Blood Marrow Transplant. 2007;13(2):235-244.

22. Trzaska KA, Rameshwar P. Current advances in the treatment of Parkinson's disease with stem cells. Curr Neurovasc Res. 2007;4(2): 99-109.

23. Abdallah BM, Kassem M. The use of mesenchymal (skeletal) stem cells for treatment of degenerative diseases: current status and future perspectives. J Cell Physiol. 2009;218(1):9-12.

24. Barbaric I, Gokhale PJ, Andrews PW. High-content screening of small compounds on human embryonic stem cells. Biochem Soc Trans. 2010; 38(4):1046-1050.

25. Laustriat D, Gide J, Peschanski M. Human pluripotent stem cells in drug discovery and predictive toxicology. Biochem Soc Trans. 2010;38(4): 1051-1057.

26. Yamanaka S. Induction of pluripotent stem cells from mouse fibroblasts by four transcription factors. Cell Prolif. 2008;41 Suppl 1:51-56.

27. Yamanaka S, Blau HM. Nuclear reprogramming to a pluripotent state by three approaches. Nature. 2010;465(7299):704-712.

28. Fierabracci A. Recent patents for isolating, delivering and tracking adult stem cells in regenerative medicine. Recent Pat Drug Deliv Formul. 2010;4(2):105-113. 
29. Maltman DJ, Przyborski SA. Developments in three-dimensional cell culture technology aimed at improving the accuracy of in vitro analyses. Biochem Soc Trans. 2010;38(4):1072-1075.

30. Danovi D, Falk A, Humphreys P, et al. Imaging-based chemical screens using normal and glioma-derived neural stem cells. Biochem Soc Trans. 2010;38(4):1067-1071.

31. Kobel S, Lutolf M. High-throughput methods to define complex stem cell niches. Biotechniques. 2010;48(4):ix-xxii.

32. Bahadduri PM, Polli JE, Swaan PW, Ekins S. Targeting drug transporters - combining in silico and in vitro approaches to predict in vivo. Methods Mol Biol. 2010;637:65-103.

33. Ishizaki T. Strategic proposals to avoid drug interactions during drug development: a lesson from a terfenadine-related drug interaction. J Toxicol Sci. 1996;21(5):301-303.

34. Roden DM. Torsade de pointes. Clin Cardiol. 1993;16(9):683-686.

35. Bradlaw JA. Evaluation of drug and chemical toxicity with cell culture systems. Fundam Appl Toxicol. 1986;6(4):598-606.

36. Gomez-Lechon MJ, Lahoz A, Gombau L, Castell JV, Donato MT. In vitro evaluation of potential hepatotoxicity induced by drugs. Curr Pharm Des. 2010;16(17):1963-1977.

37. Donato MT, LahozA, Castell JV, Gomez-Lechon MJ. Cell lines: a tool for in vitro drug metabolism studies. Curr Drug Metab. 2008;9(1):1-11.

38. Pol A, Bergers M, van Ruissen F, Pfundt R, Schalkwijk J. A simple technique for high-throughput screening of drugs that modulate normal and psoriasis-like differentiation in cultured human keratinocytes. Skin Pharmacol Appl Skin Physiol. 2002;15(4):252-261.

39. Tremblay PL, Berthod F, Germain L, Auger FA. In vitro evaluation of the angiostatic potential of drugs using an endothelialized tissue-engineered connective tissue. J Pharmacol Exp Ther. 2005;315(2):510-516.

40. Nirmalanandhan VS, Sittampalam GS. Stem cells in drug discovery, tissue engineering, and regenerative medicine: emerging opportunities and challenges. J Biomol Screen. 2009;14(7):755-768.

41. Augello A, Kurth TB, De Bari C. Mesenchymal stem cells: a perspective from in vitro cultures to in vivo migration and niches. Eur Cell Mater. 2010;20:121-133.

42. Keung AJ, Healy KE, Kumar S, Schaffer DV. Biophysics and dynamics of natural and engineered stem cell microenvironments. Wiley Interdiscip Rev Syst Biol Med. 2010;2(1):49-64.

43. Gardner RL. Stem cells and regenerative medicine: principles, prospects and problems. C R Biol. 2007;330(6-7):465-473.

44. Greenberger JS, Goff JP, Bush J, et al. Expansion of hematopoietic stem cells in vitro as a model system for human tissue engineering. Orthop Clin North Am. 2000;31(3):499-510.

45. Anzalone R, Lo Iacono M, Corrao S, et al. New emerging potentials for human Wharton's jelly mesenchymal stem cells: immunological features and hepatocyte-like differentiative capacity. Stem Cells Dev. 2010;19(4):423-438.

46. Barry FP, Murphy JM. Mesenchymal stem cells: clinical applications and biological characterization. Int J Biochem Cell Biol. 2004;36(4): 568-584.

47. Beyer Nardi N, da Silva Meirelles L. Mesenchymal stem cells: isolation, in vitro expansion and characterization. Handb Exp Pharmacol. 2006(174):249-282.

48. Minguell JJ, Erices A, Conget P. Mesenchymal stem cells. Exp Biol Med (Maywood). 2001;226(6):507-520.

49. Tocci A, Forte L. Mesenchymal stem cell: use and perspectives. Hematol J. 2003;4(2):92-96.

50. Singh SK, Clarke ID, Hide T, Dirks PB. Cancer stem cells in nervous system tumors. Oncogene. 2004;23(43):7267-7273.

51. Reya T, Morrison SJ, Clarke MF, Weissman IL. Stem cells, cancer, and cancer stem cells. Nature. 2001;414(6859):105-111.

52. Al-Hajj M, Becker MW, Wicha M, Weissman I, Clarke MF. Therapeutic implications of cancer stem cells. Curr Opin Genet Dev. 2004; $14(1): 43-47$.

53. Bonnet D, Dick JE. Human acute myeloid leukemia is organized as a hierarchy that originates from a primitive hematopoietic cell. Nat Med. 1997;3(7):730-737.
54. Croker AK, Allan AL. Cancer stem cells: implications for the progression and treatment of metastatic disease. J Cell Mol Med. 2008; 12(2):374-390.

55. Dalerba P, Cho RW, Clarke MF. Cancer stem cells: models and concepts. Annu Rev Med. 2007;58:267-284.

56. Rice KN, Jamieson CH. Molecular pathways to CML stem cells. Int J Hematol. 2010;91(5):748-752.

57. Rubnitz JE, Gibson B, Smith FO. Acute myeloid leukemia. Hematol Oncol Clin North Am. 2010;24(1):35-63.

58. Yamazaki H, Nishida H, Iwata S, Dang NH, Morimoto C. CD90 and CD110 correlate with cancer stem cell potentials in human T-acute lymphoblastic leukemia cells. Biochem Biophys Res Commun. 2009; 383(2):172-177.

59. Bomken S, Fiser K, Heidenreich O, Vormoor J. Understanding the cancer stem cell. Br J Cancer. 2010;103(4):439-445.

60. Brown P, Smith FO. Molecularly targeted therapies for pediatric acute myeloid leukemia: progress to date. Paediatr Drugs. 2008;10(2): 85-92.

61. Martinelli G, Iacobucci I, Papayannidis C, Soverini S. New targets for Ph+ leukaemia therapy. Best Pract Res Clin Haematol. 2009;22(3): 445-454.

62. Li Z, Bao S, Wu Q, et al. Hypoxia-inducible factors regulate tumorigenic capacity of glioma stem cells. Cancer Cell. 2009;15(6):501-513.

63. Guzman ML, Rossi RM, Karnischky L, et al. The sesquiterpene lactone parthenolide induces apoptosis of human acute myelogenous leukemia stem and progenitor cells. Blood. 2005;105(11):4163-4169.

64. Amore BM, Gibbs JP, Emery MG. Application of in vivo animal models to characterize the pharmacokinetic and pharmacodynamic properties of drug candidates in discovery settings. Comb Chem High Throughput Screen. 2010;13(2):207-218.

65. LeBaron MJ, Rasoulpour RJ, Klapacz J, Ellis-Hutchings RG, Hollnagel HM, Gollapudi BB. Epigenetics and chemical safety assessment. Mutat Res. 2010;705(2):83-95.

66. Shah A, Garzon-Muvdi T, Mahajan R, Duenas VJ, Quinones-Hinojosa A. Animal models of neurological disease. Adv Exp Med Biol. 2010;671: $23-40$.

67. Guguen-Guillouzo C, Corlu A, Guillouzo A. Stem cell-derived hepatocytes and their use in toxicology. Toxicology. 2010;270(1):3-9.

68. Das T, Cagan R. Drosophila as a novel therapeutic discovery tool for thyroid cancer. Thyroid. 2010;20(7):689-695.

69. Giacomotto J, Segalat L. High-throughput screening and small animal models, where are we? Br J Pharmacol. 2010;160(2):204-216.

70. Gosai SJ, Kwak JH, Luke CJ, et al. Automated high-content live animal drug screening using $\mathrm{C}$. elegans expressing the aggregation prone serpin alpha1-antitrypsin Z. PloS One. 2010;5(11):e15460.

71. Smith KA, Rex EB, Komuniecki RW. Are Caenorhabditis elegans receptors useful targets for drug discovery: pharmacological comparison of tyramine receptors with high identity from C. elegans (TYRA-2) and Brugia malayi (Bm4). Mol Biochem Parasitol. 2007;154(1):52-61.

72. Link EM, Hardiman G, Sluder AE, Johnson CD, Liu LX. Therapeutic target discovery using Caenorhabditis elegans. Pharmacogenomics. 2000;1(2):203-217.

73. Pagliarini RA, Xu T. A genetic screen in Drosophila for metastatic behavior. Science. 2003;302(5648):1227-1231.

74. Plowman GD, Sudarsanam S, Bingham J, Whyte D, Hunter T. The protein kinases of Caenorhabditis elegans: a model for signal transduction in multicellular organisms. Proc Natl Acad Sci USA.1999;96(24): $13603-13610$

75. Tickoo S, Russell S. Drosophila melanogaster as a model system for drug discovery and pathway screening. Curr Opin Pharmacol. 2002; 2(5):555-560.

76. Shulman JM, Shulman LM, Weiner WJ, Feany MB. From fruit fly to bedside: translating lessons from Drosophila models of neurodegenerative disease. Curr Opin Neurol. 2003;16(4):443-449.

77. Bates GP, Hockly E. Experimental therapeutics in Huntington's disease: are models useful for therapeutic trials? Curr Opin Neurol. 2003;16(4): $465-470$. 
78. Gunawardena S, Her LS, Brusch RG, et al. Disruption of axonal transport by loss of huntingtin or expression of pathogenic polyQ proteins in Drosophila. Neuron. 2003;40(1):25-40.

79. Zambrowicz BP, Sands AT. Knockouts model the 100 best-selling drugs - will they model the next 100? Nat Rev. 2003;2(1):38-51.

80. Zambrowicz BP, Turner CA, Sands AT. Predicting drug efficacy: knockouts model pipeline drugs of the pharmaceutical industry. Curr Opin Pharmacol. 2003;3(5):563-570.

81. Spradling A, Drummond-Barbosa D, Kai T. Stem cells find their niche. Nature. 2001;414(6859):98-104.

82. Pieper AA, Xie S, Capota E, et al. Discovery of a proneurogenic, neuroprotective chemical. Cell. 2010;142(1):39-51.

83. Furutani-Seiki M, Wittbrodt J. Medaka and zebrafish, an evolutionary twin study. Mech Dev. 2004;121(7-8):629-637.

84. Mitani H, Kamei Y, Fukamachi S, et al. The medaka genome: why we need multiple fish models in vertebrate functional genomics. Genome Dyn. 2006;2:165-182.

85. Scholz S, Mayer I. Molecular biomarkers of endocrine disruption in small model fish. Mol Cell Endocrinol. 2008;293(1-2):57-70.

86. Kitambi SS, McCulloch KJ, Peterson RT, Malicki JJ. Small molecule screen for compounds that affect vascular development in the zebrafish retina. Mech Dev. 2009;126(5-6):464-477.

87. Sukardi H, Ung CY, Gong Z, Lam SH. Incorporating zebrafish omics into chemical biology and toxicology. Zebrafish. 2010;7(1):41-52.

88. Currie PD, Schilling TF, Ingham PW. Small-scale marker-based screening for mutations in zebrafish development. Methods Mol Biol. 2008;461:493-512.

89. Haffter P, Nusslein-Volhard C. Large scale genetics in a small vertebrate, the zebrafish. Int J Dev Biol. 1996;40(1):221-227.

90. Biechele TL, Camp ND, Fass DM, et al. Chemical-genetic screen identifies riluzole as an enhancer of Wnt/beta-catenin signaling in melanoma. Chem Biol. 2010;17(11):1177-1182.
91. Chia NY, Chan YS, Feng B, et al. A genome-wide RNAi screen reveals determinants of human embryonic stem cell identity. Nature. 2010; 468(7321):316-320.

92. Jiang SQ, Paulus H. A high-throughput, homogeneous, fluorescence polarization assay for inhibitors of hedgehog protein autoprocessing. J Biomol Screen. 2010;15(9):1082-1087.

93. Lang DA, Hadley DM, Teasdale GM, Macpherson P, Teasdale E. Gadolinium-DTPA enhanced magnetic resonance imaging in human head injury. Acta Neurochir (Wien). 1990;51:293-295.

94. Thorne CA, Hanson AJ, Schneider J, et al. Small-molecule inhibition of Wnt signaling through activation of casein kinase 1alpha. Nat Chem Biol. 2010;6(11):829-836.

95. Rubin LL. Stem cells and drug discovery: the beginning of a new era? Cell. 2008;132(4):549-552.

96. Jozefczuk J, Prigione A, Chavez L, Adjaye J. Comparative analysis of human embryonic stem cell and induced pluripotent stem cellderived hepatocyte-like cells reveals current drawbacks and possible strategies for improved differentiation. Stem Cells Dev. 2011;20(7): 1259-1275.

97. Park IH, Lerou PH, Zhao R, Huo H, Daley GQ. Generation of humaninduced pluripotent stem cells. Nat Protoc. 2008;3(7):1180-1186.

98. Kanemura Y. Development of cell-processing systems for human stem cells (neural stem cells, mesenchymal stem cells, and iPS cells) for regenerative medicine. Keio J Med. 2010;59(2):35-45.

99. Knorr DA, Kaufman DS. Pluripotent stem cell-derived natural killer cells for cancer therapy. Transl Res. 2010;156(3):147-154.

100. Schwarz SC, Schwarz J. Translation of stem cell therapy for neurological diseases. Transl Res. 2010;156(3):155-160.

101. Visvader JE, Lindeman GJ. Cancer stem cells in solid tumours: accumulating evidence and unresolved questions. Nat Rev. 2008;8(10): 755-768.
Stem Cells and Cloning: Advances and Applications

\section{Publish your work in this journal}

Stem Cells and Cloning: Advances and Applications is an international, peer-reviewed, open access journal. Areas of interest in stem cell research include: Embryonic cell stems; Adult stem cells; Blastocysts; Cordblood stem cells; Stem cell transformation and culture; Therapeutic cloning; Umbilical cord blood and bone marrow cells; Laboratory,

\section{Dovepress}

animal and human therapeutic studies; Philosophical and ethical issues related to stem cell research. This journal is indexed on CAS. The manuscript management system is completely online and includes a quick and fair peer-review system. Visit http://www.dovepress.com/ testimonials.php to read real quotes from published authors 